\title{
Survival from primary abdominal lymphoma presenting with a mass and obstructive jaundice
}

\author{
Hugh J FREEMAN MD, ANDREW M SEAL MD
}

HJ FREEMAN, AM SEAL. Survival from primary abdominal lymphoma presenting with a mass and obstructive jaundice. Can J Gastroenterol 1996;10(2):89-92. A 68-year-old female presented with an enlarged and nontender palpable gallbladder and clinical features of obstructive jaundice. Subsequent laboratory investigations confirmed the presence of cholestasis associated with an obstructing mass in the region of the common hepatic duct. Pathological evaluation of the mass revealed a localized abdominal lymphoma. Treatment with chemotherapy and radiation resulted in complete clinical remission (for almost 14 years at the last evaluation). Primary abdominal lymphoma may involve the hilar region and present as a localized mass. Precise tissue diagnosis is essential to permit an aggressive management approach with the potential for significant clinical benefit.

Key Words: B cell lymphoma, Bile duct obstruction, Courvoisier gallbladder, Jaundice, Non-Hodgkin's lymphoma
Survie après un lymphome abdominal primaire accompagné d'une masse et de jaunisse obstructive

RÉSUMÉ : Patiente de 68 ans présentant une vésicule biliaire hypertrophiée, palpable, mais non sensible et des caractéristiques cliniques de jaunisse obstructive. Les épreuves de laboratoire subséquentes ont confirmé la présence de cholestase associée à une masse obstructive à la région du canal hépatique commun. L'évaluation pathologique de la masse a révélé la présence d'un lymphome abdominal localisé. La chimiothérapie et la radiothérapie ont donné lieu à une rémission clinique complète (pendant près de 14 ans suivant la dernière évaluation). Le lymphome abdominal primaire peut porter atteinte à la région hilaire et se présenter sous la forme d'une masse localisée. Le diagnostic histologique précis est essentiel pour qu'une approche thérapeutique énergique soit instaurée et que la patiente en bénéficie significativement sur le plan clinique.
$E^{x}$ xtrahepatic biliary ductal obstruction with lymphoma is a rare cause of jaundice and an even rarer manifestation of lymphoma (1). Primary lymphoma arising in the abdomen may remain localized in the hepatic hilar region leading to an abdominal mass and biliary ductal obstruction; this was recently described for the first time in the English literature in a patient from Hong Kong (2). In that patient, however, the clinical follow-up after biliary tract stenting, surgery and chemotherapy was limited to just over one year.
The patient described here presented with clinical and laboratory features of painless jaundice due to an extrahepatic biliary ductal obstruction, which was initially believed to be due to pancreatic carcinoma. Subsequent studies, however, revealed the unusual finding of a localized B cell lymphoma. Now, after completion of chemotherapy and radiation treatment almost 14 years ago, she remains in clinical remission with no evidence of recurrent disease.

Departments of Medicine (Gastroenterology) and Surgery, University of British Columbia, Vancouver, British Columbia

Correspondence and reprints: Dr Hugh Freeman, ACU F-137, Gastroenterology, Vancouver Hospital (UBC Site), 2211 Wesbrook Mall, Vancouver, British Columbia V6T 1W5. Telephone 604-822-7216, fax 604-822-7236

Received for publication May 1, 1995. Accepted July 31, 1995 


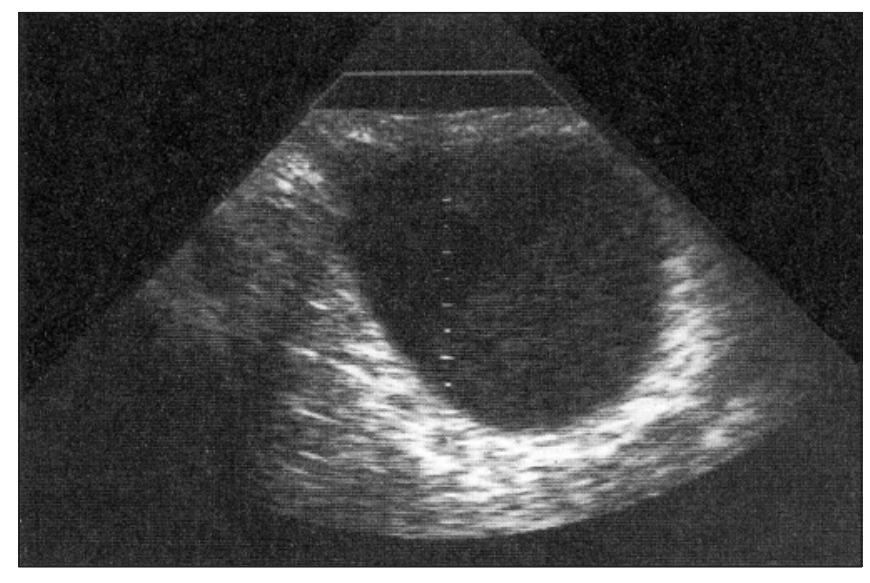

Figure 1) Abdominal ultrasound showing distended gallbladder

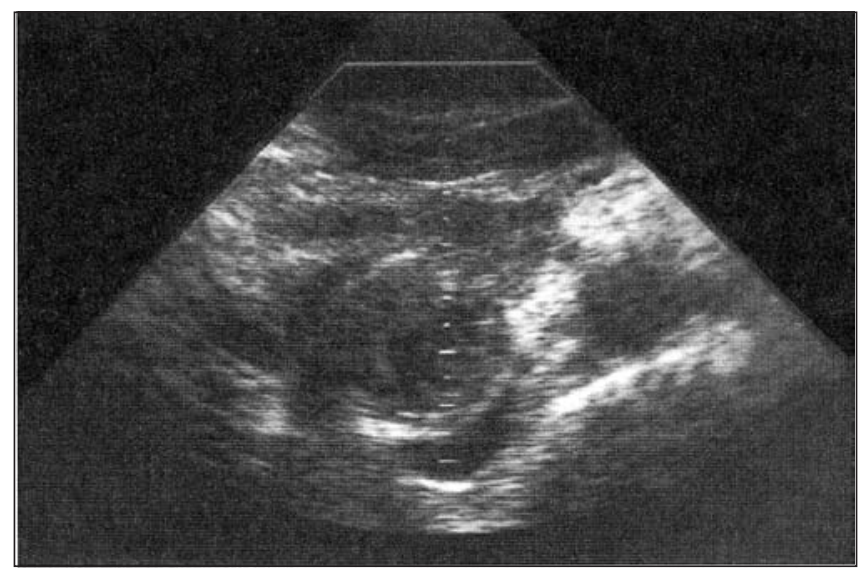

Figure 2) Abdominal ultrasound showing mass lesion in the region of the porta hepatis

\section{CASE PRESENTATION}

A 68-year-old female was admitted to hospital in October 1981 after three to four weeks of anorexia and fatigue followed by the onset of intense pruritus, dark urine, pale stools and jaundice. Examination revealed scleral icterus, linear dermal excoriations on her extremities and a rounded, smooth and nontender mass in the right upper quadrant, typical of a distended gallbladder. There was no lymphadenopathy.

Laboratory studies revealed hemoglobin, $129 \mathrm{~g} / \mathrm{L}$ (normal 120 to 160 ); white blood cell count, $4.6 \times 10^{9} / \mathrm{L}$ (normal 4.0 to 11.0 ); platelets, $280 \times 10^{9} / \mathrm{L}$ (normal 140 to 350 ); prothrombin time, $10.8 \mathrm{~s}$ (normal 10.5 to 12.5 ); serum bilirubin, $11.2 \mathrm{mg} / \mathrm{dL}$ (normal 0.07 to 1.04); alkaline phosphatase, 383 IU/L (normal 23 to 97); and aspartate aminotransferase, 186 IU/L (normal 22 to 47). Serum creatinine, electrolytes and amylase were normal.

Abdominal ultrasound revealed a distended gallbladder (Figure 1) as well as dilated intrahepatic and extrahepatic bile ducts with a $5 \mathrm{~cm}$ mass near the pancreas (Figure 2). No hepatic metastatic lesions were seen. Aspiration needle bi-

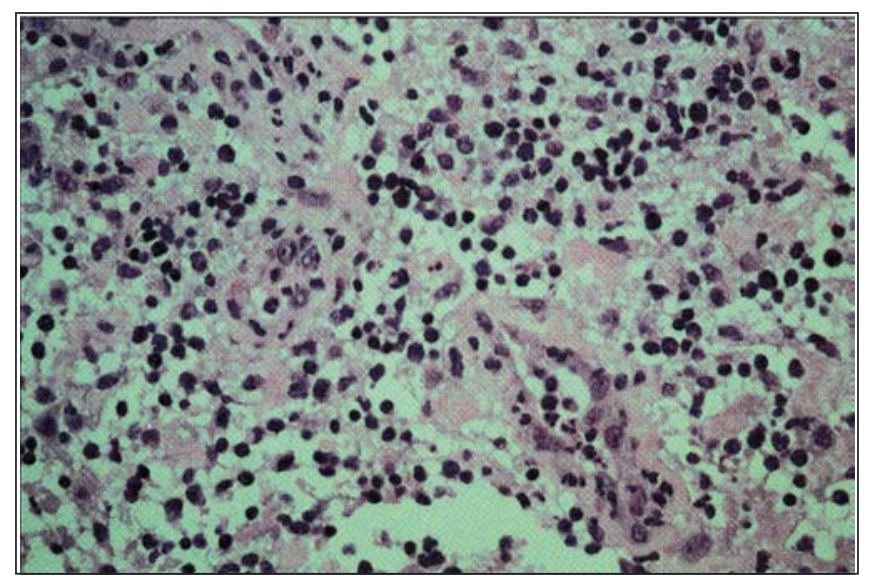

Figure 3) Aspiration needle biopsy of mass lesion in Figure 2 showing cytologically atypical lymphoid cells consistent with poorly differentiated lymphocytic lymphoma

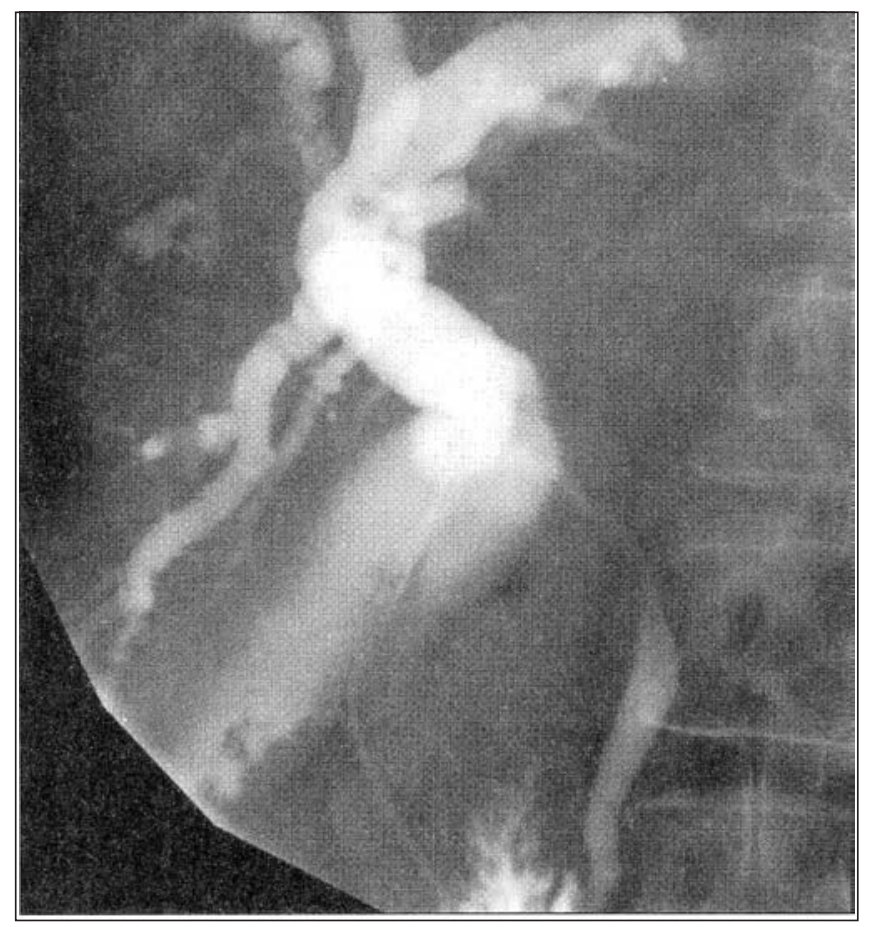

Figure 4) Intraoperative cholangiogram showing dilated intrahepatic ducts with narrowing of the midportion of the common hepatic duct

opsy of the mass revealed atypical lymphoid cells consistent with a poorly differentiated lymphocytic lymphoma (Figure $3)$. Bone marrow aspiration and trephine biopsy revealed no lymphoma. A transhepatic cholangiogram showed dilation of the intrahepatic bile ducts and the proximal common hepatic duct.

An enlarged gallbladder with a firm mass in the region of the porta hepatis displacing normal pancreas was revealed during laparotomy. Frozen sections of the mass confirmed the presence of malignant lymphoma. An operative cholangiogram (Figure 4) showed dilated intrahepatic and extrahepatic ducts with marked narrowing of the common hepatic duct 


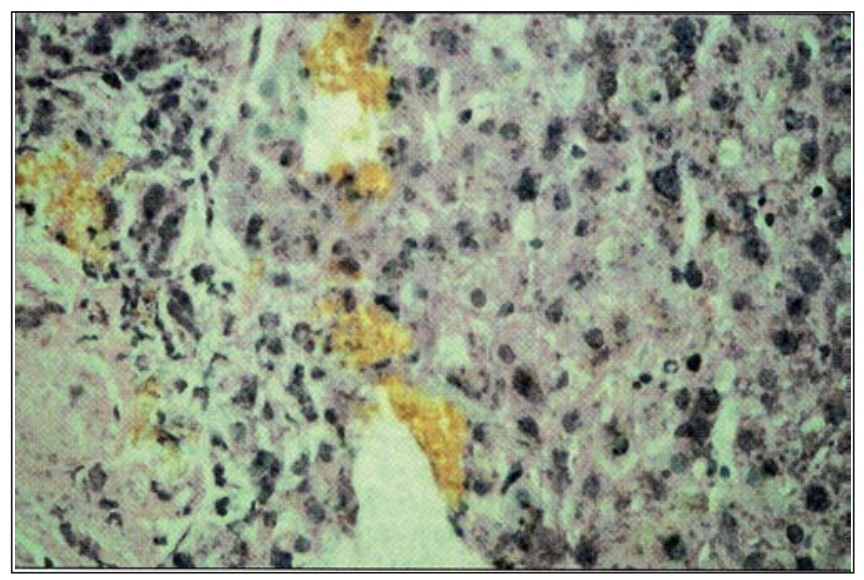

Figure 5) Liver biopsy showing typical features of large bile duct obstruction

over a $4 \mathrm{~cm}$ segment, approximately $2 \mathrm{~cm}$ distal to a patent cystic duct; this narrowed portion of bile duct was smooth and regular. The distal common bile duct was normal. A biopsy from the left lobe of the liver revealed features of large duct obstruction only (Figure 5), while a biopsy of the mass revealed fibrous tissue infiltrated with neoplastic lymphoid and histiocytic cells (Figure 6). Electron microscopy showed tumour cells typical of lymphoma.

Cholecystojejunostomy and jejunojejunostomy were done, from which the patient recovered without complication. After discharge, she was treated with three cycles of CHOP chemotherapy (cyclophosphamide, doxorubicin hydrochloride, vincristine and prednisone) and local upper abdominal radiation (30 Gy). A computerized tomographic abdominal scan in January 1982 and April 1982 revealed no residual disease.

The patient was reviewed each year, and in November 1988, a further abdominal computerized tomographic scan was normal. At her last formal evaluation in November 1994 after completion of chemotherapy and radiation treatment, she remained in clinical remission with no evidence of recurrent disease. Blood tests, including liver chemistry tests, and repeat abdominal computerized tomographic scan were normal.

\section{DISCUSSION}

The patient's clinical presentation suggested a malignant biliary obstruction, possibly in the pancreas. Indeed, the clinical finding of a palpable and nontender gallbladder in the presence of jaundice (Courvoisier's sign) due to an extrahepatic biliary ductal obstruction has traditionally been regarded as a typical clinical sign of an obstructing pancreatic carcinoma. However, the importance of definitive histological diagnosis was underlined by the detection of lymphoma and this patient's later clinical course, as well as by her subsequent response to treatment with chemotherapy and radiation with no evidence of recurrent or systemic disease.

The patient's response to treatment sharply contrasts with the poor prognosis in disseminated lymphoma complicated by biliary ductal obstruction, despite various treatment regi-

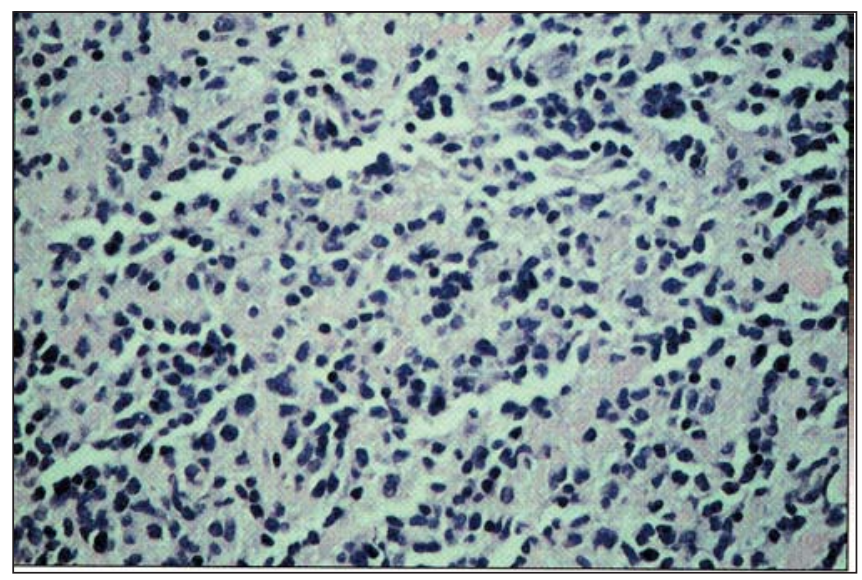

Figure 6) Operative biopsy of mass lesion at the porta hepatis fibrous tissue infiltrated with a malignant lymphoma

mens $(1,3,4)$. In addition, biliary ductal obstruction is usually considered a poor prognostic indicator for lymphoma (4). In recent years, however, some reports have described therapeutic successes in patients with primary pancreatic lymphoma $(3,5)$. Thus, even in the absence of lymphadenopathy, an intra-abdominal mass could be due to a localized lymphoma; in this setting, a precise diagnosis may permit aggressive management and a positive patient outcome.

The causes of jaundice in patients with Hodgkin's and non-Hodgkin's lymphoma have been previously enumerated (6). Often, infiltration of the liver occurs (7). Other causes that have been described include intrahepatic cholestasis, hepatotoxicity due to chemotherapeutic agents used for treatment, superimposed hepatic infections including viral hepatitis or tuberculosis, sclerosing cholangitis, vanishing bile duct syndrome and amyloidosis $(1,8-12)$. Jaundice due to obstruction from more generalized involvement of lymph nodes in lymphoma is very uncommon $(1,3,4)$, and even more rare are descriptions of lymphoma in the liver, bile ducts, pancreas and gastrointestinal tract causing jaundice $(3,5,13-20)$. Although localized lymphoma in the porta hepatis region has been described following liver transplantation (21), there is only one recent report of de novo primary lymphoma causing obstructive jaundice (2). In some patients, a definite cause for jaundice may not be defined; in these, a paraneoplastic phenomenon may play a role in some of the patients (22).

\section{CONCLUSIONS}

The present report describes a rare presentation of lymphoma localized to the porta hepatis. The tumour mass caused obstructive jaundice and was initially thought to be a pancreatic carcinoma. A precise tissue diagnosis of lymphoma, however, led to chemotherapy and radiation treatment with resultant long term survival, for almost 14 years at the last evaluation. 


\section{REFERENCES}

1. Boddie AW, Eisenberg BL, Mullins JD, et al. The diagnosis and treatment of obstructive jaundice secondary to malignant lymphoma: a problem in multidisciplinary management. J Surg Oncol 1980;14:11-23.

2. Chu KM, Lai ECS, Fan ST. Primary lymphoma presenting as intraabdominal mass and obstructive jaundice. Am J Gastroenterol 1995;90:482-4.

3. Young IF, Roberts-Thomson IC, Sullivan JR. Histiocytic lymphoma presenting with extrahepatic biliary obstruction: a report of three cases. Aust NZ J Surg 1981;51:181-3.

4. Feller E, Schiffman FJ. Extrahepatic biliary obstruction by lymphoma. Arch Surg 1990;125:1507-9.

5. Borrowdale R, Strong RW. Primary lymphoma of the pancreas. Aust NZ J Surg 1994;64:444-6.

6. Bremer JJ. Hepatic manifestations of lymphoma. Ann Clin Lab Sci 1984;14:252-60.

7. Ultmann JE, Morah EM. Clinical course and complications in Hodgkin's disease. Arch Intern Med 1973;131:331-52.

8. Lieberman DA. Intrahepatic cholestasis due to Hodgkin's disease. J Clin Gastroenterol 1986;8:304-7.

9. Groth CG, Hellstrom K, Hofvendahl S, et al. Diagnosis of malignant lymphoma at laparotomy disclosing intrahepatic cholestasis. Acta Chir Scand 1972;138:186-9.

10. Sherlock P, Winawer SJ, Lacher MJ, et al. Gastrointestinal manifestations of Hodgkin's disease. In: Lacher MJ, ed. Hodgkin's Disease. New York: John Wiley, 1976:292-310.

11. Trewby PN, Portman B, Binkley DM, et al. Liver disease as presenting manifestation of Hodgkin's disease. Q J Med 1979;189:137-50.
12. Hubscher SG, Lumley MA, Elias E. Vanishing bile duct syndrome: a possible mechanism for intrahepatic cholestasis in Hodgkin's lymphoma. Hepatology 1993;17:70-7.

13. Ryoo JW, Manaligod JR, Walker MJ. Primary lymphoma of the liver. J Clin Gastroenterol 1986;8:308-11.

14. Collins MH, Orazi A, Bauman M, et al. Primary hepatic B-cell lymphoma in a child. Am J Surg Pathol 1993;17:1182-6.

15. Nguyen GK. Primary extranodal non-Hodgkin's lymphoma of the extrahepatic bile ducts: report of a case. Cancer 19982;50:2218-22.

16. Kosuge T, Makuuchi M, Ozaki H, et al. Primary lymphoma of the common bile duct. Hepatogastroenterology 1991;38:235-8.

17. Tuchek JM, De Jong SA, Pickleman J. Diagnosis, surgical intervention, and prognosis of primary pancreatic lymphoma. Am Surg 1993;59:513-8.

18. Radhakrishnan S, Nakib BA, Liddawi HA, et al. Primary gastro-intestinal lymphoma complicated by common bile duct obstruction: report of two cases. Am J Gastroenterol 1986;81:691-4.

19. Colby TV, LaBrecque DR. Lymphoreticular malignancy presenting as fulminant hepatic disease. Gastroenterology 1982;82:339-45.

20. Zafrani ES, Leclercq B, Vernant JP, Pinaudeau Y, Chomette G, Dhumeaux D. Massive blastic infiltration of the liver: a cause of fulminant hepatic failure. Hepatology 1983;3:428-32.

21. Moody AR, Wilson SR, Greig PD. Non-Hodgkin lymphoma in the porta hepatis after orthotopic liver transplantation: sonographic findings. Radiology 1992;182:867-70.

22. Watterson J, Priest JR. Jaundice as a paraneoplastic phenomenon in a T-cell lymphoma. Gastroenterology 1989;97:1319-22. 


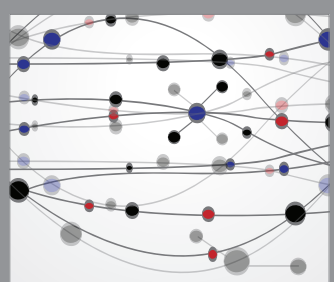

The Scientific World Journal
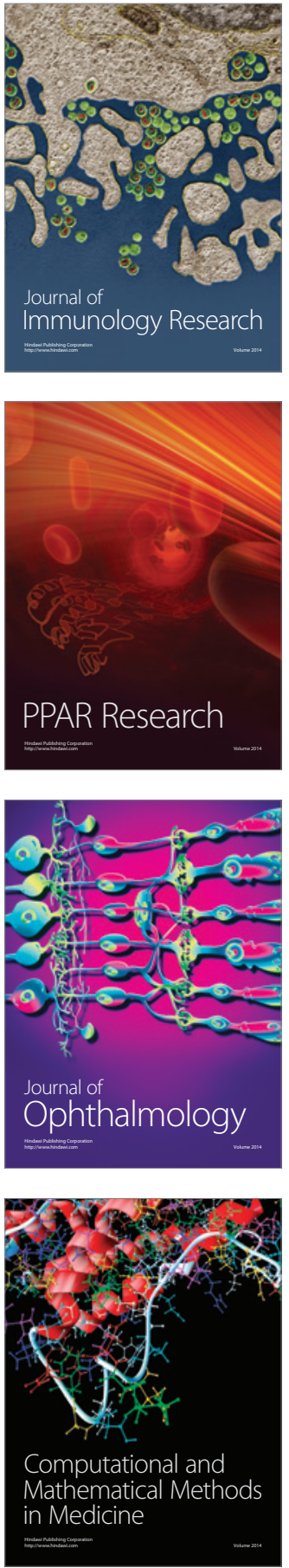

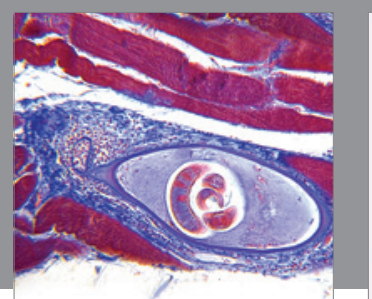

Gastroenterology Research and Practice

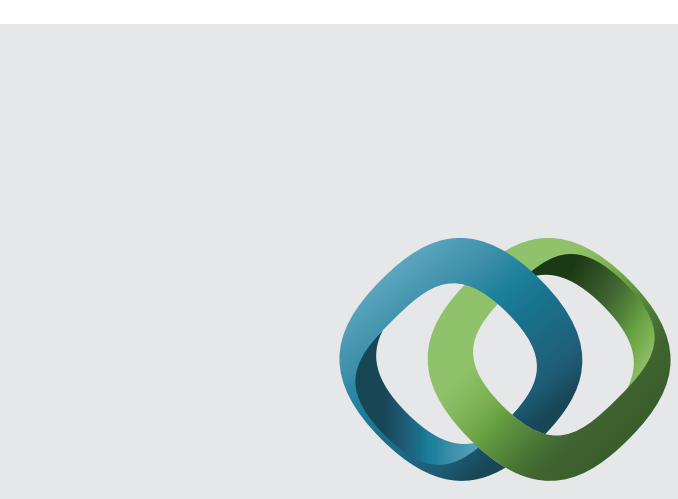

\section{Hindawi}

Submit your manuscripts at

http://www.hindawi.com
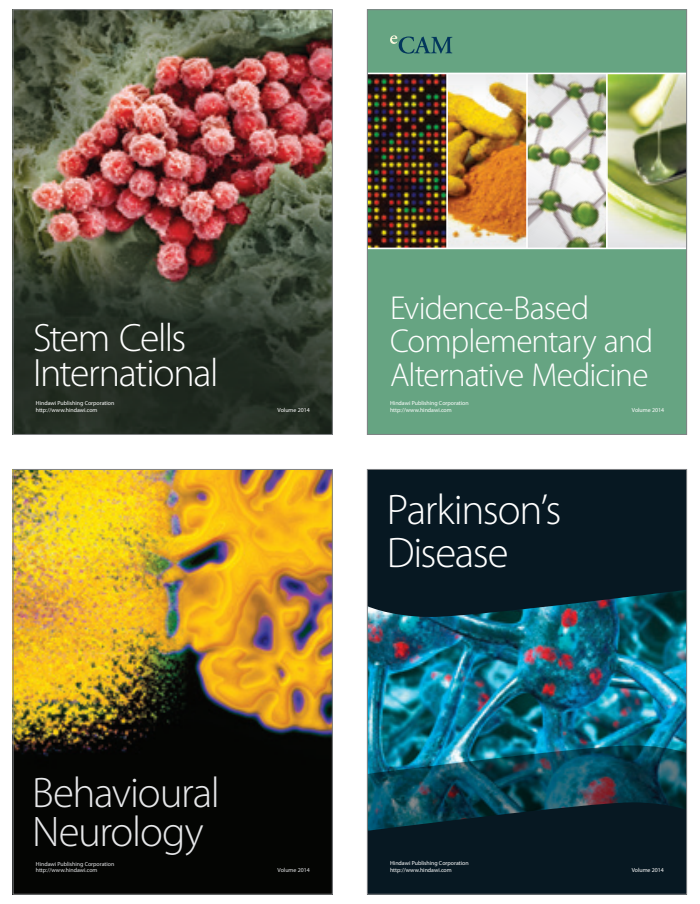
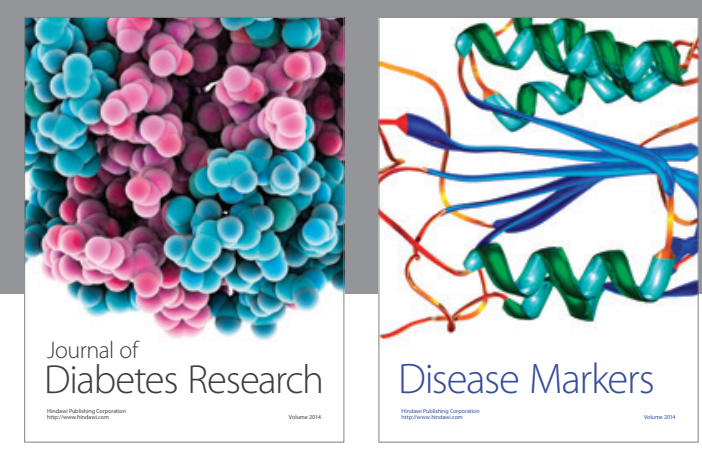

Disease Markers
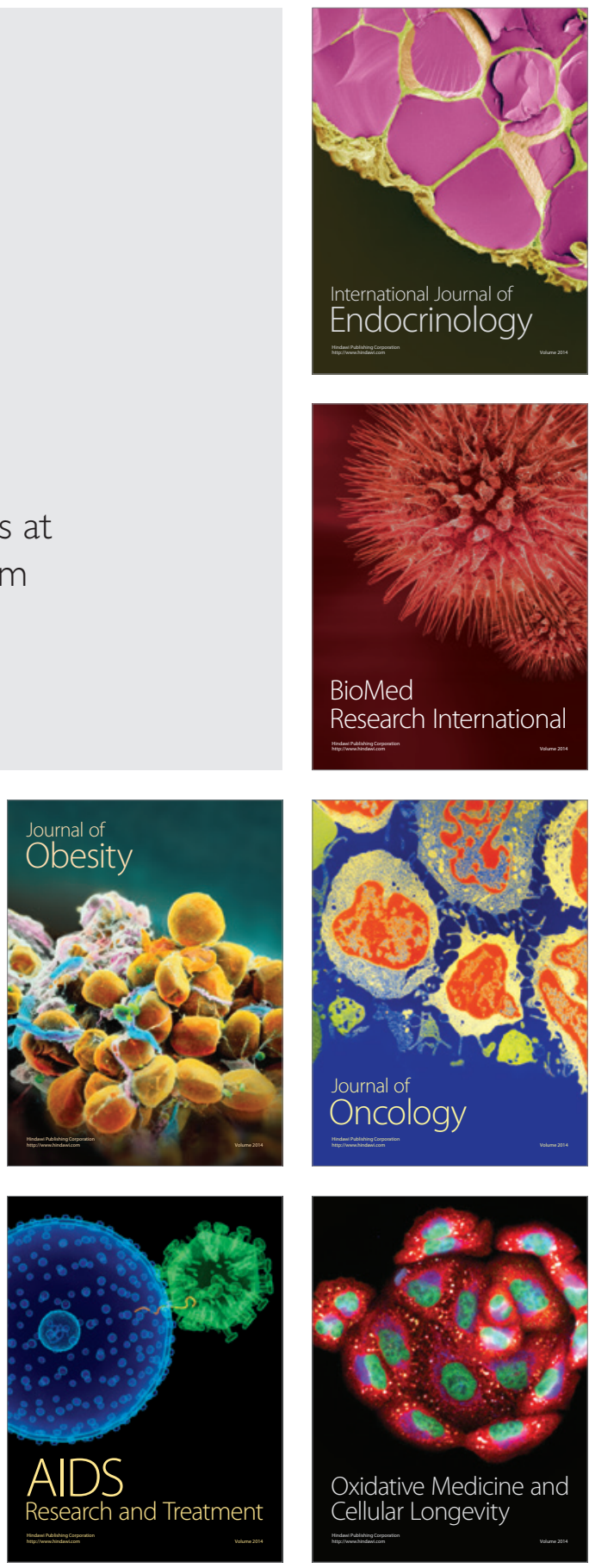